\title{
PENILAIAN PRAKTEK ILLEGAL, UNREPORTED AND \\ UNREGULATED FISHING PADA PUKAT CINCIN DI KOTA KENDARI
}

\author{
Mohammad Rais ${ }^{1)}$, Faisal Abdaud ${ }^{2)}$, Parman $^{3)}$ \\ ${ }^{1)}$ Program Studi Pemanfaatan Sumberdaya Perikanan Universitas Muhammadiyah Kendari \\ ${ }^{2}$ Program Studi Ilmu Hukum Universitas Muhammadiyah Kendari \\ ${ }^{3)}$ Yayasan Bajo Bangkit
}

\begin{abstract}
ABSTRAK
Praktek Illegal, Unreported dan Unregulated fishing (IUU Fishing) merupakan salah satu permasalahan sektor perikanan yang berdampak ekonomi, sosial dan ekologi. Pemerintah telah mengeluarkan berbagai kebijakan untuk mengatasi masalah tersebut. Hingga saat ini data dan informasi yang terkait dengan permasalahan IUU fishing pada berbagai wilayah pengelolaan perikanan di Indonesia masih sangat kurang, kebanyakan kajian yang ada masih bersifat umum. Pukat cincin Salah satu alat tangkap yang banyak dijumpai di Pelabuhan Perikanan Samudera (PPS) Kendari. Tercatat ada sekitar 21.235 ton sumberdaya perikanan yang didaratkan oleh berbagai jenis armada penangkapan (PPS Kendari, 2016). Kondisi ini berpotensi menciptakan praktek - praktek IUU fishing, sehingga diperlukan adanya kajian terkait hal tersebut. Tujuan dari penelitan ini adalah mengetahui tingkat kepatuhan armada kapal pukat cincin di PPS Kendari terhadap praktek IUU Fishing serta mengidentifikasi jenis pelanggarannya serta merumuskan rekomendasi strategi penanggulannya. Penelitian dilaksanakan pada Mei sampai dengan September 2018 di Pelabuhan Perikanan Samudera Kendari. Metode penelitian yang digunakan yaitu metode survey. Data yang dikumpulkan terdiri dari data primer dan sekunder. Instrumen utama penelitian adalah kuisioner. Hasil penelitian menunjukkan Tingkat kepatuhan armada pukat cincin di Pelabuhan Perikanan Samudera Kendari terhadap praktek IUU Fishing sangat bervariasi tergantung aspeknya. Tingkat kepatuhan pada aspek Illegal lebih tinggi dibandingkan dengan aspek unreported dan unregulated. Jenis - jenis pelanggaran IUU Fishing adalah Pencatatatn loogbook hasil tangkapan tidak sesuai dengan kenyataannya, tidak melaporkan lokasi penangkapan dengan baik dan tidak meregistrasi rumpon yang digunakan.
\end{abstract}


Rekomendasi Strategi penyelesaian yang paling efektif adalah penegakan hukum dan pemberian sanksi administrasi.

Kata kunci : IUU Fishing, PPS Kendari, Pukat cincin

\section{PENDAHULUAN}

Salah satu permasalahan utama yang saat ini mendapat perhatian dalam pengelolaan sumberdaya perikanan di Indonesia adalah isu Ilegal, Unreported and Unregulated (IUU) Fishing dan saat ini telah menjadi isu global. FAO (2001) telah merumuskan panduan khusus untuk membantu mengatasi kegiatan IUU fishing yang dikenal dengan nama International Plan of Action to Prevent, Determine and Eliminate IUU fishing (IPOA-IUU fishing), pedoman tersebut bertujuan untuk mencegah, menghambat dan menghilangkan kegiatan IUU fishing dengan menyiapkan langkah-langkah pengelolaan sumber daya perikanan yang komprehensip, terintegrasi, efektif, transparan serta memperhatikan kelestarian sumber daya bagi negara-negara perikanan dunia (Neka, 2010). Dokumen dimaksud pada bagian awalnya berisikan pemahaman mengenai arti dan istilah (Illegal, unreported dan unregullated). Di beberapa wilayah di Indonesia, kenyataan yang ada saat ini fenomena IUU fishing masih banyak terjadi dan pemerintah telah melakukan upaya-upaya untuk mengantisipasi dengan mengeluarkan beberapa peraturan tentang perikanan, dan pengawasan. Kementerian Kelautan dan Perikanan (KKP) telah mengeluarkan berbagai kebijakan yang terkait dengan IUU fishing, antara lain (1) Permen KP No.56/PERMENKP/2014 tentang penghentian sementara (moratorium) perizinan usaha perikanan tangkap di wilayah pengelolaan perikanan negara Republik Indonesia, (2) Permen KP No. 57/PERMENKP/2014 tentang Perubahan Kedua Atas Permen KP No.30/MEN/2012 tentang Usaha Perikanan Tangkap di Wilayah Pengelolaan Perikanan Republik Indonesia yang memuat larangan transhipment atau bongkar muat ikan di tengah laut; (3) Permen KP No.1/PERMENKP/2015 tentang Penangkapan Lobster (Panulirus spp.), Kepiting (Scylla spp.) dan Rajungan (Portunus pelagicus.); serta (4) Permen KP No. 2/ PERMENKP/2015 tentang Larangan Penggunaan Alat Penangkapan Ikan Pukat Hela (Trawl) dan Pukat Tarik (Seine Net) di Wilayah Pengelolaan Perikanan Negara Republik Indonesia.

Wilayah perairan Kota Kendari secara geografis berbatasan langsung dengan Laut Banda (bagian timur - barat) sehingga memiliki potensi sumberdaya perikanan tangkap yang cukup tinggi. Data laporan statistik Pelabuhan Perikanan Samudera (PPS) Kendari tahun 2015 mencatat sekitar 21.235 ton produksi sumberdaya perikanan tangkap yang dimanfaatkan dari perairan Sulawesi Tenggara didominasi oleh alat tangkap pukat cincin 
sebanyak 325 buah (PPS Kendari, 2016). Potensi sumberdaya ikan yang ada didominasi oleh ikan jenis ekonomis penting seperti Tuna, Cakalang dan Tongkol. Tingginya potensi sumberdaya perikanan di Kota Kendari memerlukan pengelolaan yang dapat menjamin keberlangsungan ikan dan pemanfaatannya.

Kendala yang dihadapai pemerintah saat ini baik di daerah ataupun pusat adalah masih kurangnya kajian penilaian terhadap praktek IUU fishing untuk level kawasan, sementara hal ini sangat berpengaruh terhadap keberlanjutan pemanfaatan sumberdaya perikanan di kawasan tertentu, sehingga perlu dilakukan upaya-upaya untuk memeranginya dengan cara melakukan penilaian kawasan tertentu apakah sudah terbebas atau tidaknya dari praktek-praktek IUU Fishing. Penilaian praktek IUU fishing dengan pendekatan kawasan akan berkontribusi dalam upaya pengelolaan perikanan secara berkelanjutan, serta membantu pemerintah dalam menyusun tahapan atau langkah-langkah yang harus dilakukan untuk mengatasi praktek IUU Fishing di Kota Kendari.Tujuan penelitian ini adalah mengetahui tingkat kepatuhan armada kapal pukat cincin di PPS Kendari terhadap praktek IUU Fishing, mengidentifikasi jenis - jenis pelanggaran IUU Fishing di PPS Kendari serta menyusun rekomendasi strategi penanggulangan IUU Fishing PPS Kendari.

Berdasarkan hal diatas maka kajian untuk menilai tingkat kepatuhan pengelolaan sumberdaya perikanan di Kota Kendari terhadap praktek IUU fishing sangat diperlukan disamping sebagai bahan informasi bagi penataan sektor perikanan di Kota Kendari juga dapat membantu pemerintah dalam menyusun rencana atau strategi dalam penanggulangan IUU fishing di Kota Kendari. 


\section{METODE PENELITIAN}

Penelitian ini dilaksanakan pada bulan Mei sampai September 2018 di Pelabuhan Perikanan Samudera (PPS) Kendari.

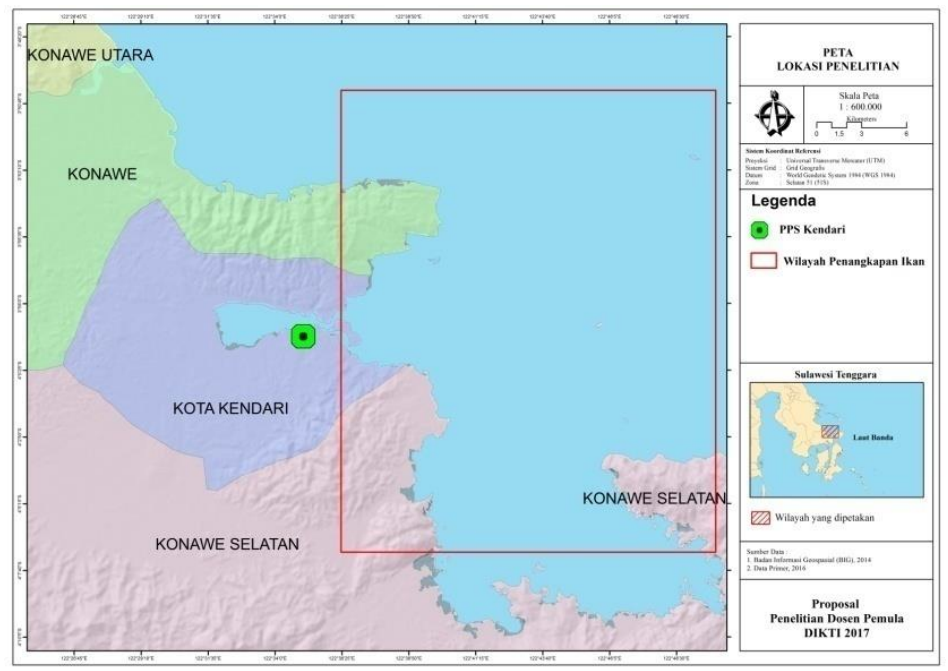

Gambar 1. Lokasi Penelitian

\section{a) Metode Pengambilan Data}

Penelitian ini menggunakan metode survey dengan objek penelitian adalah armada kapal Pukat Cincin yang mendaratkan hasil tangkapannya di Pelabuhan Perikanan Samudera (PPS) Kendari. Data yang dikumpulkan terdiri dari data primer dan sekunder. Data primer diperoleh dari beberapa responden dengan menggunakan metode purposive sampling, untuk memudahkan proses wawancara maka digunakan kuisioner yang terdiri dari beberapa pertanyaan yang dipersyaratkan dalam analisis IUU Fishing. Adapun responden dan jumlah sampel dapat dilihat pada Tabel 1. Data sekunder diperoleh dengan melakukan studi literatur dan data dari intansi pelabuhan perikanan samudera kendari yang terkait dengan tujuan penelitian

Tabel 1. Klasifikasi responden target

\begin{tabular}{llc}
\hline No & \multicolumn{1}{c}{ Responden Target } & Jumlah Responden \\
\hline $\mathbf{1}$ & Nelayan (ukuran kapal < 30 GT) & 30 responden \\
$\mathbf{2}$ & Nelayan (ukuran kapal > 30 GT) & 30 responden \\
$\mathbf{3}$ & Pengelola PPS Kendari & 5 responden \\
$\mathbf{4}$ & $\begin{array}{l}\text { Pengawasan Sumberdaya Kelautan dan Perikanan } \\
\text { (PSDKP) Provinsi Sulawesi Tenggara }\end{array}$ & 5 responden \\
& & \\
\hline
\end{tabular}


5 Lembaga Swadaya Masyarakat (LSM) 3 responden

\section{b) Tahapan Penelitian}

Pencapaian tujuan penelitian sangat terkait dengan tahapan pelaksanaan penelitian, agar tujuan dapat tercapai dengan baik. Berikut ini tahapan penelitian yang akan dilakukan, yaitu :

1. Koordinasi dengan tim peneliti dan enumerator (mahasiswa)

Kegiatan ini bertujuan untuk memperoleh kesamaan persepsi tentang cara pengumpulan data, penentuan target responden serta mekanisme pelaksanaan dilapangan agar waktu dapat dimanfaatkan secara efektif dan efisien.

2. Koordinasi dengan instansi terkait

Tahap selanjutnya adalah melakukan koordinasi dengan instansi terkait, khususnya instansi PPS Kendari, Dinas Kelautan dan Perikanan Prov. Sulawesi Tenggara dan PSDKP Prov. Sulawesi Tenggara agar memudahkan proses identifikasi dan penentuan responden dan pengumpulan data sekunder.

3. Wawancara Responden dan pengumpulan data sekunder

Tim peneliti yang dibantu dengan enumerator melakukan wawancara dengan responden terpilih menggunakan kuisioner yang telah disiapkan sebelumnya. Data yang dikumpulkan terkait dengan aktivitas setiap armada pukat cincin (sampel responden nelayan) meliputi praktek-praktek illegal, unrepoted dan unregulated.

4. Tabulasi data dan analisis data

Hasil wawancara dan data sekunder yang dikumpulkan, kemudian akan dianalisis untuk mengetahui jenis - jenis pelanggaran IUU Fishing serta menyusun strategi penanganannya.

\section{c) Metode Analisis Data}

\section{Analisis IUU Fishing}

Analisis IUU Fishing menggunakan pendekatan yang dikembangan oleh WWF Indonesia (WWF Indonesia, 2014), pendekatan ini bersifat semi kuantitatif dengan metode bobot dan skoring. Analisis ini sangat berguna untuk mengetahui sejauh mana praktek praktek IUU fishing terjadi dalam sebuah kawasan secara cepat dan akurat. Seluruh komponen yang dianalisis (Tabel 2) telah tercantum dalam kuisioner. 
Tabel 2. Komponen analisis IUU Fishing

\begin{tabular}{|c|c|}
\hline Komponen IUU Fishing & Sub komponen \\
\hline \multirow[t]{7}{*}{ Illegal Fishing } & Pendaftaran dan pendataan kapal \\
\hline & Perizinan usaha perikanan tangkap \\
\hline & Ketentuan anak buah kapal \\
\hline & $\begin{array}{l}\text { Ketaatan wilayah operasi, jenis dan } \\
\text { spesifikasi alat tangkap dan alat bantu } \\
\text { penangkapan ikan }\end{array}$ \\
\hline & Kelayakan operasi kapal ikan \\
\hline & $\begin{array}{l}\text { Penangkapan spesies target yang sudah } \\
\text { diatur }\end{array}$ \\
\hline & $\begin{array}{l}\text { Tangkapan sampingan (by-catch) } \\
\text { termasuk spesies yang dilindungi }\end{array}$ \\
\hline \multirow[t]{5}{*}{ Unreported Fishing } & $\begin{array}{l}\text { Transhipment dilaut dan bongkar muat } \\
\text { di pelabuhan }\end{array}$ \\
\hline & $\begin{array}{l}\text { Ketentuan tentang sertifikasi hasil } \\
\text { tangkapan }\end{array}$ \\
\hline & Sistem pemantauan kapal (VMS) \\
\hline & Pelaksanaan logbook penangkapan ikan \\
\hline & Pemantauan diatas kapal \\
\hline Unregulated Fishing & Kebijakan pengelolaan perikanan \\
\hline
\end{tabular}

Setiap pertanyaan terdiri dari 3 jawaban yang berberda dan akan diberi skor 1,2 dan 3, kemudian pembobotan diberikan terhadap kualitas data dan derajat kepentingannya. Adapun nilai pembobotan berkisar antara 1,2 dan 3. Selanjutnya akan dilakukan perkalian antara skor dan bobot antara skor jawaban dengan nilai bobot pertanyaannya. Hasil akhir dari analisis ini adalah kategorisasi tingkat pelanggaran IUU Fishing yang terjadi (Tabel 3). 
Tabel 3. Kategorisasi penilaian IUU Fishing

\begin{tabular}{cc}
\hline Kategorisasi IUU Fishing & Skor (persentase) \\
\hline Pelanggaran rendah & $<25 \%$ \\
Pelanggaran sedang & $>25-75 \%$ \\
Pelanggaran tinggi & $>75 \%$ \\
\hline
\end{tabular}

\section{HASIL DAN PEMBAHASAN}

Tingkat kepatuhan kapal pukat cincin di PPS Kendari terhadap praktek IUU Fishing

Tingkat kepatuhan armada kapal pukat cincin di Pelabuhan Perikanan Samudera Kendari terhadap praktek IUU Fishing sangat bervariasi tergantung aspeknya. Tingkat kepatuhan pada aspek Illegal lebih tinggi dibandingkan dengan aspek unreported dan unregulated.

Tabel 4. Tabulasi tingkat kepatuhan Armada kapal Pukat cincin

\begin{tabular}{|c|c|c|c|c|c|}
\hline No & Indeks & Parameter Strategis (PS) & Skor & Bobot & Total \\
\hline \multirow[t]{11}{*}{1} & Illegal Fishing & $\begin{array}{l}\text { 1. Pendaftaran kapal yang dibuktikan } \\
\text { dengan Buku Kapal Perikanan }\end{array}$ & 3 & 3 & 9 \\
\hline & & $\begin{array}{l}\text { 2. Tanda pengenal kapal perikanan } \\
\text { pada lambung kapal }\end{array}$ & 3 & 2 & 6 \\
\hline & & $\begin{array}{l}\text { 3. Pengurangan nilai bobot (mark } \\
\text { down) kapal dari ukuran sebenarnya }\end{array}$ & 3 & 3 & 9 \\
\hline & & 4. SIUP & 3 & 3 & 9 \\
\hline & & 5. SIPI/SIKPI kapal ikan > 5GT & 3 & 3 & 9 \\
\hline & & 6. Bukti Pencatatan Kapal $(\mathrm{BPK})<5$ & 3 & 3 & 9 \\
\hline & & GT & & & \\
\hline & & 7. KII di WPP-NRI menggunakan & 3 & 2 & 6 \\
\hline & & $\begin{array}{lll}\text { Nakhoda dan } & \text { ABK }\end{array}$ & & & \\
\hline & & Berkewarganegaraan Indonesia & & & \\
\hline & & $\begin{array}{l}\text { 8. Sertifikat Nakhoda dan Juru Mesin } \\
\text { (Ankapin/Atkapin atau SKK) }\end{array}$ & 1 & 2 & 2 \\
\hline
\end{tabular}


9. Kepatuhan wilayah operasi/lokasi penangkapan/pengangkutan ikan sesuai dengan tercantum di SIPI/SIKPI

10. Kepatuhan penggunaan API sesuai SIPI

11. Kepatuhan penggunaan alat bantu lampu

12. Izin penggunaan rumpon

13. Pelanggaran penangkapan di lokasi zona inti Kawasan Konservasi

Perairan

14. penerapan Surat Laik Operasi $\quad 3 \quad r \begin{array}{lll}2 & 6\end{array}$ (SLO)

15. Penerapan SPB/SIB

16. Kepatuhan aturan lobster, kepiting, 2 rajungan, napoleon, dan tuna sirip biru

17. Penangkapan ikan yang dilindungi 3 (by-catch)

2

Unreported

1. Transhipment

3

Fishing

2. SHTI

4. Logbook Perikanan

5. Pengisian Logbook Perikanan

6. Observer

1. Pencatatan penangkapan nelayan kecil 
3. Pengaturan pengelolaan perikanan

berbasis kuota untuk spesies target, jumlah kapal berdasarkan ukuran

dan alat tangkap, ukuran ikan yang

layak tangkap, atau pembatasan

waktu tangkapan

4. Modifikai alat tangkap

Kapal armada pukat cincin di pelabuhan perikanan samudera kendari menunjukkan tingkat pelanggaran sedang. Hasil analisis proporsi tingkat kepatuhan atau penilaian tingkat pelanggaran dapat dilihat pada gambar 2 .

Gambar 2 . Tingkat Pelanggaran IUU Fishing armada Pukat cincin

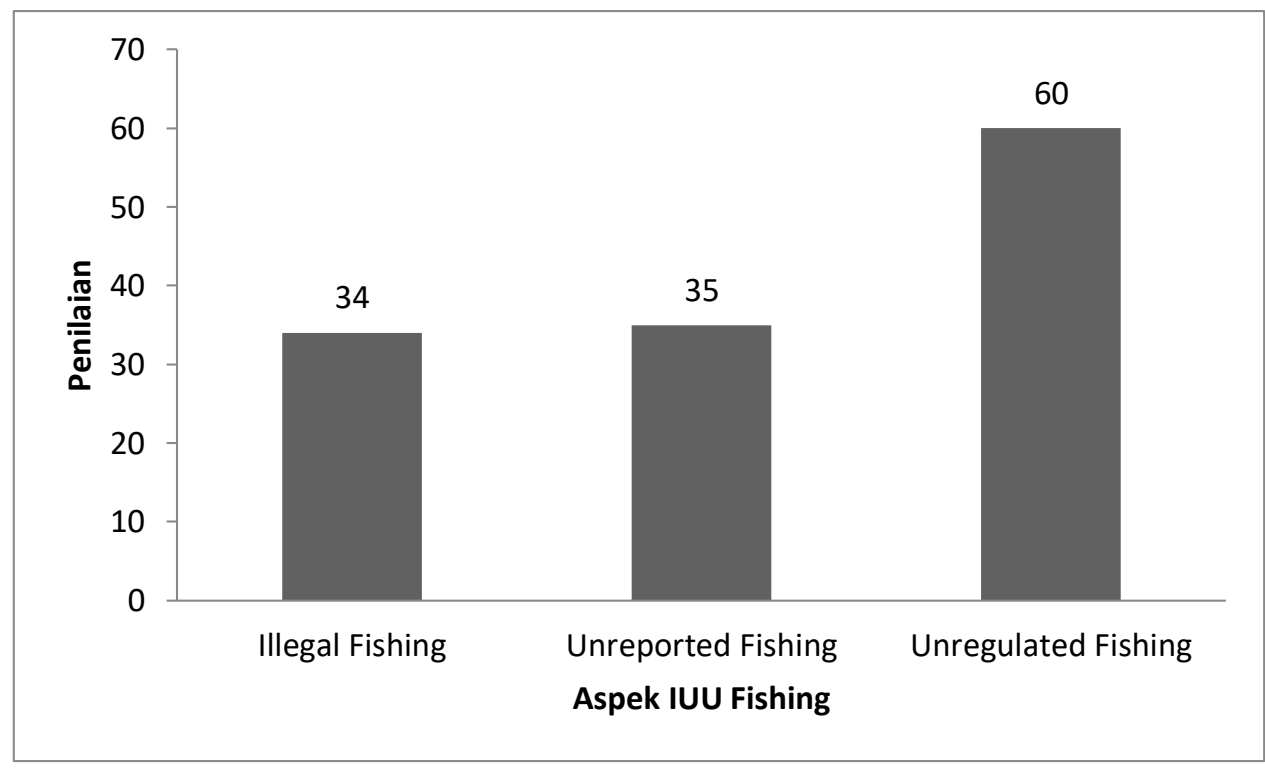

Aspek Illegal fishing diartikan sebagai aktifitas usaha perikanan yang dilakukan dengan tidak mengindahkan aspek keberlanjutan sumberdaya perikanan atau menggunakan alat tangkap yang sifatnya merusak sumberdaya dan ekosistem (FAO.2001). Aspek ini paling banyak memiliki indikator penilaian dibandingkan dengan aspek yang lainnya meskipun tingkat kepentingan pada setiap unsur tersebut berbeda satu dengan yang lain dalam menilai tingkat kepatuhan atau tingkat pelanggaran suatu alat tangkap. Hasil penelitian menunjukkan bahwa dari setiap responden yang ditanyakan berkaitan dengan seluruh unsur dalam aspek illegal memberikan penilaian tingkat pelanggarannya sedang dengan nilai $34 \%$. Hal ini disebabkan karena tingkat penertiban administrasi kapal sebagai syarat untuk melakukan operasi penagkapan ikan sudah ditingkatkan menjadi pusat pelayanan terpadu satu pintu. Hal ini memudahkan para nelayan untuk memenuhi 
seluruh administrasi perijinan sebelum melakukan penangkapan sehingga seluruh data kapal telah tercatat di Syahbandar PPS Kendari. Selain itu, penegakan hukum kepada nelayan yang tidak patuh dalam pengurusan dokumen kapal akan dikenakan sanksi administrasi yaitu tidak dikeluarkannya surat ijin berlayar sehingga para nelayan berusaha untuk menerapkan seluruh prinsip illegal fishing ini. Armada kapal pukat cincin di pelabuhan perikanan samudera kendari telah mematuhi beberapa kompenen pada aspek Illegal fishing yaitu telah memiliki buku kapal perikanan sebagai tanda bahwa kapal tersebut telah terdaftar di pelabuhan. Tanda pengenal kapal perikanan pada lambung kapal pukat cincin juga sudah terpasang. Sejak tahun 2015 seluruh kapal pukat cincin telah dilakukan pengukuran ulang bobot kapal yang selama ini terjadi mark down. Telah memiliki Surat Izin Usaha Perikanan (SIUP) dan Surat Izin Penangkapan Ikan (SIPI)/Surat Izin Kapal Penangkap Ikan (SIKPI). Seluruh ABK armada kapal pukat cincin adalah Warga Negara Indonesia (WNI) dan tidak melakukan praktek "pinjam bendera" (Flag of Convenience -FOC) sebagaimana banyak kasus pada perairan yang lain bahwa praktek praktek FOC merupakan salah satu bentuk aksi pencurian ikan dari negara lain (Dahuri. 2017). Kapal pukat cincin juga tidak melakukan penangkapan di daerah lokasi zona inti kawasan konservasi perairan atau beroperasi di daerah karang karena rata rata kedalaman jaring pukat cincin adalah 100 meter. Setiap armada kapal yang akan melakukan trip penangkapan harus dilengkapi dengan Surat Laik Operasi (SLO) dan juga merupakan syarat penerbitan SIB

Unreported fishing diartikan sebagai kegiatan usaha perikanan yang tidak dilaporkan seperti jumlah hasil tangkapan dan lokasi penangkapan kepada pihak terkait termasuk juga aktivitas bongkar muat ikan di tengah laut (FAO.2001). Rata-rata responden menyampaiakn bahwa proses pelaporan hasil tangkapan dan lokasi penangkapan tidak dilakukan sesuai dengan yang sebenarnya. Salah satu alasan yang membuat para nelayan tidak melaporkan hasil tangkapan dengan baik adalah untuk menghindari tingginya pajak. Pajak dihitung berdasarkan jumlah hasil tangkapan yang dilaporkan ke pihak pelabuhan. Selain itu, nelayan juga tidak melaporkan daerah penangkapan ikan secara detail dengan lokasi penangkapan dan hanya melaporkan range daerah penangkapan ikan sehingga kesulitan melacak ikan hasil tangkapan bersal dari daerah mana. Dampak terburuk dari unreported adalah kurangnya data ikan di pelabuhan yang menjadi bahan untuk menganalisis berapa jumlah stok ikan yang berada di dalam suatu perairan. Kesalahan dalam memunculkan informasi jumlah stok akan berdampak buruk terhadap sumberdaya ikan. Nilai pelanggaran pada aspek ini adalah $35 \%$ dengan kategori pelanggaran sedang. Unregulated fishing adalah usaha perikanan yang 
dilakukan tidak sesuai dengan ketentuan peraturan atau kebijakan suatu negara atau hukum internasional yang berlaku (FAO. 2001)

\section{d) Menyusun rekomendasi strategi penanggulangan IUU Fishing PPS Kendari}

Berdasarkan hasil penelitian IUU Fishing yang dilakukan di PPS Kendari pada alat tangkap purse seine, maka dapat kami rekomendasi beberapa hal yang dapat membantu terlaksananya upaya pengelolaan perikanan yang berkelanjutan di Sulawesi Tenggara.

1. Nilai indeks illegal fishing menunjukkan nilai tertinggi dibandingkan indeks lainnya, hal ini memberi gambaran perlunya prioritas perbaikan pada aspek tersebut. Beberapa hal yang harus dilakukan yaitu (1) perlunya program sertifikasi bagi nahkoda dan juru mesin kapal purse seine, (2) perlunya pendataan sebaran rumpon yang beroperasi mengingat alat bantu ini sangat efektif untuk mengumpulkan ikan karena bersifat permanen, (3) Perlunya sosialiasi yang efektif tentang lokasi kawasan konservasi khususnya di wilayah Sulawesi Tenggara.

2. Untuk aspek unreported fishing hal yang harus ditata yaitu (1) program observer diatas kapal harus dilakukan secara kontinyu agar tingkat keakurata data perikanan dapat ditingkatkan, (2) pemantauan dalam penggunaan VMS agar lebih diperhatikan.

Aspek unregulated fishing yang paling penting berdasarkan hasil kajian ini adalah (1) perlunya penerapan pengelolaan perikanan berbasis kuota oleh PPS Kendari dan DKP Prov. Sulawesi Tenggara, mengingat alat tangkap purse seine merupakan jenis alat tangkap yang paling efektif menangkap ikan yang bersifat schooling (bergerombol), sehingga jika tidak diatur akan menyebabkan potensi overfishing beberapa jenis ikan seperti layang, cakalang dan tongkol akan semakin tinggi. (2) Perlunya dilakukan pendataan kapal bagang yang beroperasi di Sulawesi Tenggara, mengingat kapal ini masih belum banyak yang memilki SIUP/SIKPI dan sering melakukan kegiatan transhipment

\section{KESIMPULAN}

Hasil penelitian yang dilakukan di Pelabuhan Perikanan Samudera Kendari Sulawesi Tenggara adalah sebagai berikut :

1. Tingkat kepatuhan armada kapal ikan di Pelabuhan Perikanan Samudera Kendari terhadap praktek Illegal, Unreported and Unregulated Fishing sangat bervariasi tergantung aspeknya. Tingkat kepatuhan pada aspek Illegal lebih tinggi dibandingkan dengan aspek unreported dan unregulated.

2. Jenis - jenis pelanggaran IUU Fishing di Pelabuhan perikanan samudera teridentifikasi setelah melakukan wawancara kepada stakeholder adalah Pencatatatn loogbook hasil 
tangkapan tidak sesuai dengan kenyataannya, Tidak melaporkan lokasi penangkapan dengan baik dan rinci dan Nelayan pada dasarnya tidak ada yang meregistrasi rumponnya baik itu jumlah maupun lokasi pemasangannya.

Penelitian lanjutan sangat perlu dilakukan terutama mengenai Lokasi pemasangan rumpon hubungannya terhadap konflik pemanfaatan daerah penangkapan ikan Perairan Laut Timur Sulawesi Tenggara.

\section{DAFTAR PUSTAKA}

Arsyad, H.H.I. 2015. Peluang dan tantangan kerjasama indonesia - filipina dalam menangani illegal fishing. Skripsi. Universitas Hasanuddin. Makassar.

David, F.R. 2007. Manajemen Strategis, edisi kesembilan. PT. Indeks Kelompok Gramedia. Jakarta.

[FAO] Food and Agriculture Organization. 2001. FAO International Plan of Action to Prevent, Deter and Eliminate Illegal, Unreported and Unregulated Fishing. Rome, FAO. 24p. http://www.fao.org/DOCREP/003/y1224E/Y1224E00.htm. Diakses tanggal 27 Mei 2017.

Jaelani, A.Q dan Basuki, U. 2014. Illegal, Unreported adn Unregulated (IUU) Fishing : Upaya mencegah dan memberantas Illegal fishing dalam membangun poros maritim Indonesia. Jurnal Supremasi Hukum. 3 (1):168-192.

Jaya, BPM. 2016. Tindakan penegakan hukum terhadap kapal asing yang melakukan illegal fishing di wilayah pengelolaan perikanan Indonesia. Skripsi. Universitas Lampung. Lampung

Naim, A. 2010. Pengawasan Pengawasan sumberdaya perikanan dalam penanganan Illegal fishing di perairan Provinsi Maluku Utara. Jurnal Ilmiah Agribisnis dan Perikanan. 3 (2): $1-14$.

Neka, A. 2010. Analisis Kebijakan Penanggulangan Illegal Fishing di Kabupaten Halmahera Utara. Tesis. Institut Pertanian Bogor. Bogor.

Nugrah, H.T. 2017. Kajian yuridis tingkat pidana illegal fishing di wilayah perairan kepulauan riau oleh aparat penegakan hukum dengan undang - undang nomor 45 tahun 2009 tentang perikanan. Skripsi. Universitas Pasundan Bandung. Bandung.

Rangkuti, F. 2001. Analisis SWOT Teknik Membedah Kasus Bisnis. Reorientasi Konsep Perencanaan Strategis untuk Abad 21. Jakarta: PT Gramedia Pustaka Utama. 
Renhoran, M. 2012. Strategi Penanganan Illegal, Unreported and Unregulated (IUU) fishing di Laut Arafura. Tesis. Universitas Indonesia. Jakarta.

Rudiansyah, B. 2015. Peran aparatur negara dalam penangan kegiatan perikanan yang tidak sah di perairan Raja Empat. Jurnal Kajian Politik dan Masalah Pembangunan. 11 (2): 1717-1730.

Sunyowati, D. 2014. Dampak kegiatan IUU fishing di Indonesia. Seminar Nasional "Peran dan Upaya Penegak Hukum dan Pemangku Kepentingan Dala Penanganan dan Pemberantasan IUU Fishing di Wilayah Perbatasan Indonesia”. 22, September 2014, Surabaya. $1-5$

[PPS] Pelabuhan Perikanan Samudera Kendari. 2016. Data Statistik Perikanan PPS Kendari tahun 2015. Kendari

Permen KP No.56/PERMENKP/2014 tentang penghentian sementara (moratorium) perizinan usaha perikanan tangkap di wilayah pengelolaan perikanan negara Republik Indonesia,

Permen KP No. 57/PERMENKP/2014 tentang Perubahan Kedua Atas Permen KP No.30/MEN/2012 tentang Usaha Perikanan Tangkap di Wilayah Pengelolaan Perikanan Republik Indonesia yang memuat larangan transhipment atau bongkar muat ikan di tengah laut

Permen KP No.1/PERMENKP/2015 tentang Penangkapan Lobster (Panulirus spp.), Kepiting (Scylla spp.) dan Rajungan (Portunus pelagicus.)

Permen KP No. 2/ PERMENKP/2015 tentang Larangan Penggunaan Alat Penangkapan Ikan Pukat Hela (Trawl) dan Pukat Tarik (Seine Net) di Wilayah Pengelolaan Perikanan Negara Republik Indonesia

WWF Indonesia. 2014. Panduan Analisis Illegal,Unreported, Unregulated (IUU) Fishing Berbasis Kawasan. WWF Indonesia. Jakarta. 